\title{
Multi-terminal DC Wind Farm Collection Grid Internal Fault Analysis and Protection Design
}

\author{
Jin Yang, Student Member, IEEE, John E. Fletcher, and John O'Reilly, Senior Member, IEEE
}

\begin{abstract}
The multi-terminal DC wind farm is a promising topology with a voltage source inverter (VSI) connection at the onshore grid. Voltage source converters (VSCs) are robust to AC side fault conditions. However, they are vulnerable to DC faults on the DC side of the converter. This paper analyses DC faults, their transients and the resulting protection issues. Overcurrent faults are analysed in detail and provide an insight into protection system design. The radial wind farm topology with star or string connection is considered. The outcomes may be applicable for VSCs in both the multi-VSC DC wind farm collection grid and VSC-based high voltage direct current (HVDC) offshore transmission systems.
\end{abstract}

Index Terms-Voltage source converter (VSC), fault overcurrent, multi-terminal DC wind farm, wind power generation.

\section{INTRODUCTION}

$\mathbf{M}$ ULTI-TERMINAL DC wind farm topologies are attracting increasing research effort. For grid connection of wind farms, the topology uses high voltage direct current transmission using voltage source converters (VSC-HVDC) [1]. With AC/DC converters on the generator side, this topology can be developed into a multi-terminal DC network for wind power collection, which is especially suitable for large-scale offshore wind farms due to advantages such as: no requirement for generator synchronisation; full-rated VSCs are capable of tracking wind turbine maximum power point; DC transmission avoids the AC transmission distance limitations for distant offshore wind farms; and system efficiency enhancement [2]-[4].

Traditional HVDC systems are robust to DC short-circuits as they are current-regulated with a large smoothing reactance connected in series with cables. Therefore, they do not suffer from overcurrents due to DC cable faults and there is no overcurrent to react to. Hence HVDC protection mainly relies on DC voltage change detection [5]. Research on HVDC system protection is mainly focused on specific cable fault locating approaches [6], [7], including application of travelling wave detection methods [8]. However, HVDC protection method is not applicable for VSC-based multi-terminal DC systems.

Voltage source conversion (VSC) techniques are commonly used for $\mathrm{AC} / \mathrm{DC}$ or DC/AC power conversion. Ideally, in a DC wind farm, each conversion element can be a voltage source, because of its flexible control of both active power and reactive power. VSC controllability can cope with grid-side AC

J. Yang and J. O'Reilly are with the Department of Electronics and Electrical Engineering, University of Glasgow, Glasgow, G12 8LT, UK (email: j.yang@elec.gla.ac.uk; j.oreilly@elec.gla.ac.uk).

J. E. Fletcher is with the Department of Electronic and Electrical Engineering, University of Strathclyde, Glasgow, G1 1XW, UK (e-mail: john.fletcher@eee.strath.ac.uk). disturbances, during which appropriate control and protection methods can be used to protect its power electronic devices [9], [10]. But due to the overcurrents flowing through freewheel diodes, it is defenceless against DC side faults, for example, DClink short-circuits, DC cable short-circuits, and DC cable ground faults. Among them, the DC side short-circuit fault is the most serious and special protections are required to tackle this critical situation. Therefore DC switchgear configuration and VSC protection systems need to be properly designed and allocated.

There have been discussions about the influence of DC faults on DC distribution systems and possible protection solutions. The methods include switchgear allocation, metal oxide varistor (MOV) connected across diodes to protect them from overvoltage, or replacing diodes with controllable gate power electronic devices [11], [12]. DC-link capacitor discharging overcurrent protection is also analysed [13]. Generally the most serious DC short-circuit faults happen at the DC rails. However, no research about the DC cable connected VSCs has been reported, in which a cable short-circuit fault is potentially more common than a DC rail fault and the impact of a DC fault on the freewheel diodes in the VSC can be worse than that of a direct DC rail short circuit due to the inductive component in the discharge path. Although the underground cables are seldom short-circuited compared to overhead lines, it is a critical condition and needs to be analysed particularly for switchgear relay and protection design. The method of transmission level meshed VSC-HVDC system fault detection and location is discussed in [14], [15]. An economic solution using AC side circuit breakers coordinating with DC fast switches (which are only used for physical isolation instead of arc-extinguishing) are proposed with a "hand-shaking" coordination approach. No detailed fault overcurrent is analysed. Moreover, AC side switchgear is apparently not fast enough to cope with the rapid rise of fault current characteristic of freewheel diode conduction which can damage power electronic devices in several milliseconds. The basic "cut-and-try" method is not enough for system reliability enhancement.

In this paper, DC cable faults, with the cable connected to a VSC, are discussed to help solve this problem. A radial topology wind farm collection and transmission system is considered. A method without switchgear configuration is proposed for smallscale DC wind farms to provide an economic option. However, for large-scale offshore DC wind farms with HVDC power transmission, DC switchgear configuration is indispensable.

The paper is organised as follows. In Section II, the multiterminal DC wind farm topology background is introduced with potential options. Then possible internal DC faults are analysed 
according to type and characteristic. Fault overcurrent expressions are given in detail. Under this characteristic analysis, fault detection and detailed protection methods are proposed in Section IV. Theoretical analysis and PSCAD/EMTDC simulations are provided in Section III, IV and V.

\section{MULTI-TERMinal DC Wind FARM}

\section{A. Multi-terminal DC Wind Farm Topology}

The multi-terminal DC wind farm topology is still a matter of research and discussion. Current limitations of DC transmission include the lack of operational experience, the high-cost of DC circuit breakers and the lag in development of DC devices for high-power applications. However, DC transmission is still an economic technique for distant large-scale offshore wind farms. Traditional solutions of $\mathrm{AC}$ wind farm collection grids use either $\mathrm{AC}$ or $\mathrm{DC}$ transmission cables [1]. $\mathrm{AC}$ distribution and transmission is a commonly-used topology, with mature technologies. Nowadays, favoured DC wind farm topologies can be classified in terms of the number and positions of voltage level transform (step-up DC/DC, or AC/DC) and detailed converter topologies. No discussions about other two aspects are evident: 1) whether radial or loop connection; 2) each DC cluster is in star or string connection as in traditional $\mathrm{AC}$ wind farm scenario. In this paper, both star and string connections are considered. The meshed connection could be promising for HVDC transmission level in the future but is not discussed.

The illustration of star or string connected DC wind farms are shown in Fig. 1. Each wind turbine-generator unit is connected with an AC/DC converter and collected to the DC system through cables. Thereafter power is transferred to the onshore grid through voltage source inverter (VSI) and step-up transformer. The DC voltage level is stepped-up with a centralised DC/DC transfer converter, which is discussed in [2] to be the optimal option for DC wind farms. DC cable grounding capacitances are only considered for long transmission cables where they can be incorporated into the DC-link capacitors at either end. DC collection cable grounding capacitances are omitted because of the low collection voltage level. Therefore, the cables are represented by series $R L$ impedance. Fig. 1 shows the possible DC switchgear configuration as well.

\section{B. DC Distribution System Fault Protection}

DC distribution fault protection issues of a stand-alone Navy shipboard power systems were discussed in [12]. The system characteristic is different to that of wind farm collection grid, mainly in the power sources and power flow direction. Traditional DC distribution can have generators of its own but is generally a load on the network; a DC wind farm is a power source, however under DC fault conditions, it will absorb power from the grid. [14], [15] study a fault locating and isolation method for a general multi-VSC-based DC system; this is mainly based on AC side circuit breakers, and no DC switchgear configuration is discussed due to cost considerations.

For star connection, each turbine-generator-converter unit has its own collection cable and switchgear that connect to a DC bus. Whereas for string connection, the turbine-generator sets are connected together with similar cable lengths. In this case, the
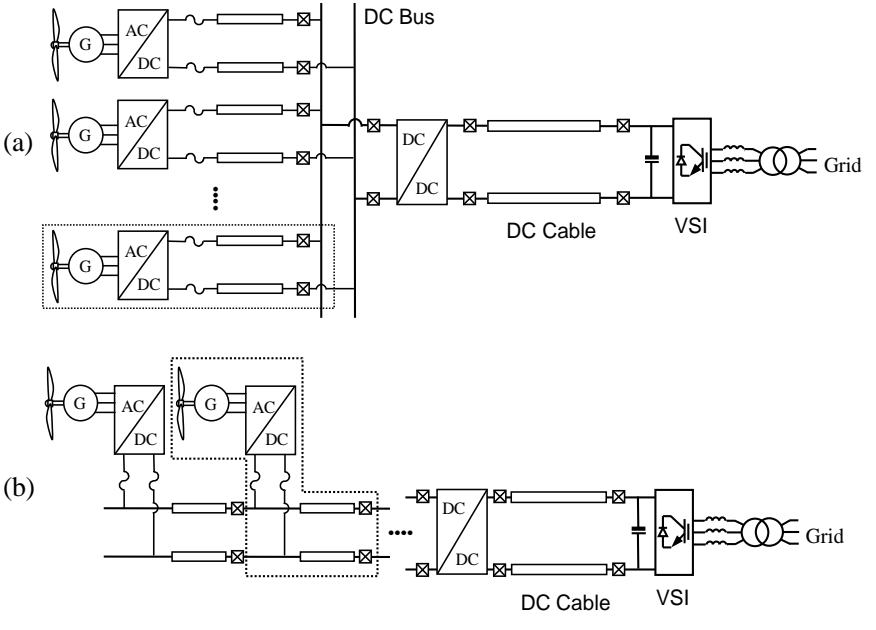

? Fuse $\quad$ Circuit Breaker / Switchgear and its Relay System

Fig. 1. DC wind farm topology with switchgear configuration: (a) star collection; (b) string collection.
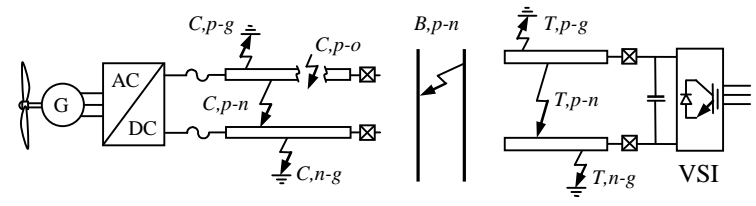

Collection Grid Unit DC Bus Transmission System

$p-n$ : Positive-negative short-circuit fault $\quad p-g$ : Positive cable ground fault

$p-o$ : Positive cable open-circuit fault $\quad n$-g: Negative cable ground fault

Fig. 2. Locations and types of DC wind farm internal faults.

collection cable rating can change along the string as transmitted power increases. The sectionalised switchgear shown in Fig. 1 (b) are usually not used in reality. Normally, each string has only one switchgear: the whole string has to be tripped if a fault occurs. To enhance the reliability, sectionalised switchgear positions are shown here. They are not only for fault isolation, but also for maintenance to enhance the wind farm availability even under maintenance.

In this case, the connection can be seen as each individual wind turbine-generator-cable section (collection grid unit, shown in Fig. 1 (a) and (b) in dotted areas), DC bus and transmission system with VSI, shown in Fig. 2. Hence the analysis can be used for both connections as different combinations of these standard components.

\section{DC FAULT TYPES AND CHARACTERISTICS}

The DC faults that may happen to wind farms can be classified into different levels: the wind turbine generation system level, the connection grid level, and the transmission level. For different devices, they can also be sorted as: inner-converter faults, DC cable faults, and junction faults, i.e. at the DC bus.

Wind power generation systems may have different topologies and the power electronic building block has its own protections, such as detailed DFIG protection [16], [17], and PMSG protection [18], [19]. Internal faults inside the converter, such as IGBT shoot-through and short-circuit across the DC rails, are typically managed by the VSC control system [12] and are less frequent than external faults on the cables or terminals that are exposed to the environment. Hence the protection of VSC internal faults is not included in this paper, which can also be solved using traditional differential protection method [5] or that of HVDC systems [20]. Therefore, this paper will focus on the 
collection grid and transmission system faults, which are shown in Fig. 2.

Cable faults happen frequently. The most common reason for cable fault is insulation deterioration and breakdown. There can be several causes [21]: physical damage (the most serious shortcircuit fault can happen because of this); environmental stresses such as damp, especially at the terminals of cables, where it is easily exposed to soil or water; electrical stresses such as overload operation or operation at high temperature; cable aging and others. These can cause a ground fault. Here, the characteristics of the DC fault current are analysed for a number of faults on the DC cable that connects the power sources to the VSI.

\section{A. VSI DC Short-Circuit Fault Overcurrent}

A DC short-circuit fault is the most serious condition for the VSI. The IGBTs can be blocked for self-protection during faults, leaving reverse diodes exposed to overcurrent. For the fault shown in Fig. 2, no matter where the DC short circuit fault happens, it can be represented by an equivalent circuit shown in Fig. 3, where $R$ and $L$ are the equivalent resistance and inductance of the cable from the VSI to the cable short-circuit point. To solve the complete response of this non-linear circuit, different time periods are analysed individually. Expressions for both the DC-link voltage and diode overcurrent are provided.

1) Immediately after the Fault (Natural Response):

This is the DC-link capacitor discharging phase as shown in Fig. 4(a). Under the condition of $R<2 \sqrt{L / C}$, the solution of second-order circuit natural response gives an oscillation. Assume the fault happens at time $t_{0}$, the natural response (without inverter side current $i_{V S I}$ ) under initial conditions of $v_{C}\left(t_{0}\right)=V_{0}, i_{L}\left(t_{0}\right)=I_{0}$ is

$$
\begin{gathered}
v_{C}=\frac{V_{0} \omega_{0}}{\omega} e^{-\delta t} \sin (\omega t+\beta)-\frac{I_{0}}{\omega C} e^{-\delta t} \sin \omega t \\
i_{L}=C \frac{d v_{C}}{d t}=-\frac{I_{0} \omega_{0}}{\omega} e^{-\delta t} \sin (\omega t-\beta)+\frac{V_{0}}{\omega L} e^{-\delta t} \sin \omega t
\end{gathered}
$$

where $\delta=\frac{R}{2 L}, \omega^{2}=\frac{1}{L C}-\left(\frac{R}{2 L}\right)^{2}, \omega_{0}=\sqrt{\delta^{2}+\omega^{2}}, \beta=\arctan \frac{\omega}{\delta}$.

The time when capacitor voltage drops to zero is

$$
t_{1}=t_{0}+(\pi-\gamma) / \omega
$$

where $\gamma=\arctan \left(\left(V_{0} \omega_{0} C \sin \beta\right) /\left(V_{0} \omega_{0} C \cos \beta-I_{0}\right)\right)$.

2) Diode Freewheel Phase (after $v_{C}=0$, Natural Response):

This is the cable inductor discharging phase which is solved using the first-order equivalent circuit, Fig. 4 (b) where the inductor current circulates in the VSI freewheel diodes. The inductor current has an initial value $i_{L}\left(t_{1}\right)=I_{0}^{\prime}$. The expression of inductor discharge current, where each phase-leg freewheel diode current carries a third of the current, is

$$
i_{L}=I_{0}^{\prime} e^{-(R / L) t}, i_{D 1}=i_{L} / 3 \text {. }
$$

This is the most challenging phase for VSI freewheel diodes, because the freewheel overcurrent is very abrupt with a high initial value, which can immediately damage the diodes.

3) Grid Side Current Feeding Phase (Forced Response):

This is the DC-link capacitor and cable inductor under a forced current source response (with $i_{V S I}$ when the VSI control blocked, $v_{C}$ is not necessarily zero), Fig. 4(c). To calculate the fault current contribution from the inverter, a three-phase short

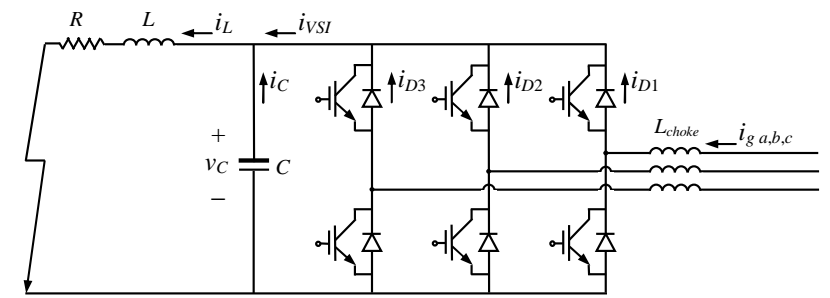

Fig. 3. VSI with cable short-circuit fault condition.
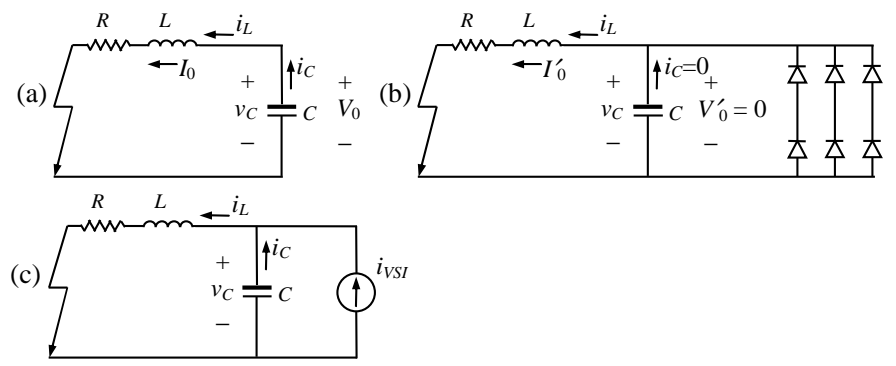

Fig. 4. Equivalent circuit with VSI as a current source during cable short circuit fault: (a) immediately after the fault (capacitor discharging phase); (b) diode freewheel phase; (c) grid current-fed phase.

circuit current expression is obtained by three-phase short circuit analysis. For phase $a$, assume the grid voltage after fault happens is $v_{g a}=V_{g} \sin \left(\omega_{s} t+\alpha\right)$, with $V_{g}$ as amplitude, $\omega_{s}$ as the synchronous angular frequency, phase $a$ voltage angle $\alpha$ at $t_{1}$, the phase current is

$i_{g a}=I_{g} \sin \left(\omega_{s} t+\alpha-\varphi\right)+\left[I_{g|0|} \sin \left(\alpha-\varphi_{0}\right)-I_{g} \sin (\alpha-\varphi)\right] e^{-t / \tau}$

where $\varphi=\arctan \left(\omega_{s}\left(L_{\text {choke }}+L\right) / R\right), \tau=\left(L_{\text {choke }}+L\right) / R, I_{g|0|}$ and

$\varphi_{0}$ are the initial grid current amplitude and phase angle, $L_{\text {choke }}$ is the grid side choke inductance.

The positive $i_{g a}$ current flows from diode $D_{1}$ to contribute to the $i_{V S I}$, with those of $i_{g b}$ and $i_{g c}$, so the total $i_{V S I}$ is the positive three phase short circuit current summation.

$$
i_{V S I}=i_{D 1}+i_{D 2}+i_{D 3}=i_{g a,(>0)}+i_{g b,(>0)}+i_{g c,(>0)} \text {. }
$$

Here phase $a$ part $i_{g a,(>0)}$ response is analysed, which is chosen to be the most serious one (with grid voltage phase angle zero at the fault initiation). Phases $b$ and $c$ can be superimposed afterwards. The inductor currents are solved as

$i_{L}=A \sin \left(\omega_{s} t+\gamma\right)+B e^{-t / \tau}+\frac{C_{1} \omega_{0}}{\omega} e^{-\delta t} \sin (\omega t+\beta)+\frac{C_{2}}{\omega} e^{-\delta t} \sin \omega t(7)$

where $A=I_{g}\left[\left(1-\omega_{s}^{2} L C\right)^{2}+\left(R C \omega_{s}\right)^{2}\right]^{-\frac{1}{2}}, \gamma=\alpha-\varphi-\theta$,

$\theta=\arctan \frac{R C \omega_{s}}{1-\omega_{s}^{2} L C}, B=I_{g n} \frac{\tau^{2}}{\tau^{2}-R C \tau+L C}, C_{1}=-(A \sin \gamma+B)$,

$C_{2}=B / \tau-\omega_{s} A \cos \gamma$.

This fault analysis can also be seen from PSCAD/EMTDC simulation (Fig. 5 and 6) with a vector controlled SPWM-VSI and DC cables. The simulation system parameters, initial values, and phase times are listed in Table I. The serious first wave front happens during the first phase and the freewheel effect happens at the beginning of phase 2, which are shown in Fig. 6. The most vulnerable component - diodes - suffer during the freewheel phase, in which the current is 73 times the normal value (from 36A to 2619A) in this case within 5ms. The capacitor suffers from a large discharging current, which can be solved by operating the dedicated DC capacitor circuit breaker [12], or adding capacitor overcurrent protection [13], or simply using fuses as for distribution system capacitor banks [22]. 


\section{4) Influence of Fault Resistance:}

Usually, the circuit will experience oscillation if $R<2 \sqrt{L / C}$. Sometimes, a small fault resistance exists between the two faulted cables. This will make $R_{f}+R>2 \sqrt{L / C}$, which results in a first order damping process. The DC-link voltage will not drop to zero, so no freewheel diode conduction occurs. In cases of short-circuit faults, fault resistances are generally small, e.g. $0.5 \Omega$. Hence the most critical phase can sometimes be avoided, only overcurrent protection for the DC-link capacitor and cables are required. The overcurrent protection relay time setting is not that critical as well. The damping only effect will be shown in cable ground fault, in which the ground resistance is always considerable.

\section{B. VSI DC Cable Ground Fault}

The ground fault analysis depends on the grounding system of the DC wind farm. Usually, the grounding points in a DC wind farm include: the neutral of the step-up transformer, and the DClink mid-point [11], [23], as shown in Fig. 7. The latter grounding point can improve the imbalance between the positive and negative currents and voltages.

A ground fault will form a ground loop with the above grounding points. The blocked voltage source will act like an uncontrolled rectifier with DC-link voltage changing to the rectified voltage, so the current will flow through the diodes. This current depends on the impedance between the transformer and the ground fault point. The difference between positive and negative faults is the direction of current and the bridge diodes that conduct. The fault resistance $R_{f}$ can not be ignored in this case, usually ground fault resistance varies from ohms to hundreds of ohms [6]. The equivalent circuit is shown in Fig. 8 for the fault calculation, which is divided into transient and steady phases.

\section{1) Transient Phase:}

The transient phase can be expressed by a third-order statespace equation

$$
\left[\begin{array}{c}
\dot{v}_{C}^{\prime} \\
\dot{i}_{L} \\
\dot{i}_{L_{\text {croke }}}
\end{array}\right]=\left[\begin{array}{ccc}
0 & -1 / 2 C & 1 / 2 C \\
1 / L & -\left(R_{f}+R\right) / L & 0 \\
-1 / L_{\text {choke }} & 0 & 0
\end{array}\right]\left[\begin{array}{c}
v_{C}^{\prime} \\
i_{L} \\
i_{L_{\text {crobec }}}
\end{array}\right]+\left[\begin{array}{c}
0 \\
0 \\
1 / L_{\text {choke }}
\end{array}\right] v_{g a, b, c}
$$

where $v_{C}, i_{L}$, and $i_{L_{\text {clooke }}}$ are the state variables, which can be solved analytically in the time-domain or s-domain. There are no particular effects on the diodes (unlike during the above short-circuit freewheel phase). Example simulation results are shown in Fig. 9. The capacitor voltage drops to zero within $30 \mathrm{~ms}$, meanwhile the inductor current experiences a large transient of $0.8 \mathrm{kA}$ (22 times rated current).

2) Steady-state Phase:

The steady-state phase can be calculated to see the most serious overcurrents. The total impedance is

$$
Z=\left(R_{f}+R+j \omega_{s} L\right)||\left(1 / j \omega_{s} C\right)+j \omega_{s} L_{\text {choke }}=|Z| \angle \theta^{\prime}
$$

Then the current through diode is

$$
i_{D 1}=i_{g a,(>0)}=\left(V_{g} /|Z|\right) \angle \alpha-\theta^{\prime} .
$$

System parameters and calculation results are shown in Table II. In simulation, it is assumed that the DC power source side is tripped immediately after the fault to avoid a DC-link capacitor overvoltage on the negative side. The steady-state diode current magnitude in simulation is $0.1663 \mathrm{kA}$, Fig. 9, which is close enough compared with calculation value of $0.1661 \mathrm{kA}$ (4.6 times of rating current).
TABLE I SIMULATION PARAMETERS AND CALCULATION INITIAL VALUES FOR SHORT-CIRCUIT FAULT

\begin{tabular}{c|c|c}
\hline Simulation system parameters & Initial values & Times \\
\hline$R=0.12 \Omega$ & $V_{0}=1.0 \mathrm{kV}(\mathrm{DC})$ & $t_{0}=0 \mathrm{~s}$ \\
\hline$L=0.56 \mathrm{mH}$ & $I_{0}=0.036 \mathrm{kA}(\mathrm{DC})$ & $t_{1}=4.44 \mathrm{~ms}$ \\
\hline$C=10 \mathrm{mF}$ & $I_{0}^{\prime}=2.619 \mathrm{kA}(\mathrm{DC})$ & \\
\hline$R=0.12<2 \sqrt{L / C}=0.473$ & $V_{g}=0.392 \mathrm{kV}(\mathrm{AC})$ & \\
\cline { 2 - 3 } & $|Z|=\left|R+\mathrm{j} \omega\left(L_{\text {choke }}+L\right)\right|=2.691$ & \\
\hline$L_{\text {choke }}=8 \mathrm{mH}$ & $I_{g}=0.392 / 2.691=0.146 \mathrm{kA}$ & \\
\hline
\end{tabular}

(a)

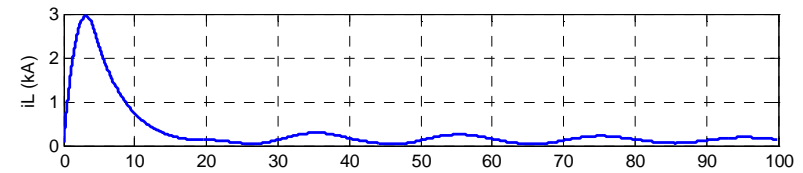

(b)

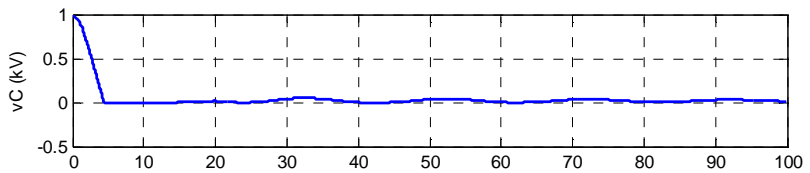

(c)

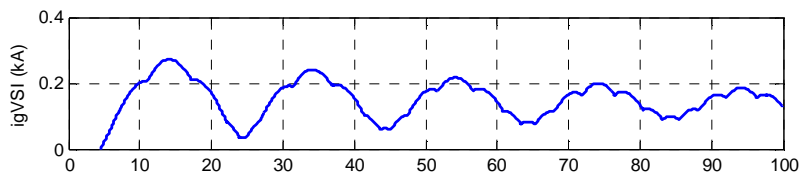

(d)

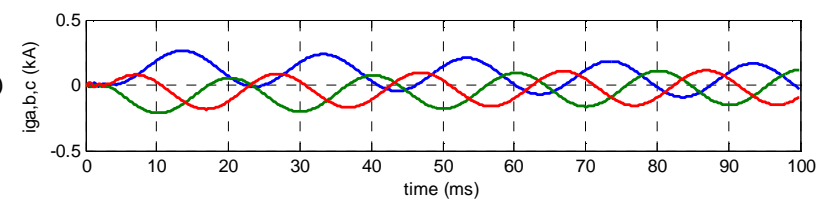

Fig. 5. VSI with cable short-circuit fault simulation: (a) cable inductor current $i_{L}$; (b) DC-link capacitor voltage $v_{C}$; (c) current provided by grid VSI $i_{g V S I}$; (d) grid side three-phase currents $i_{g a, b, c}$ ).

(a)

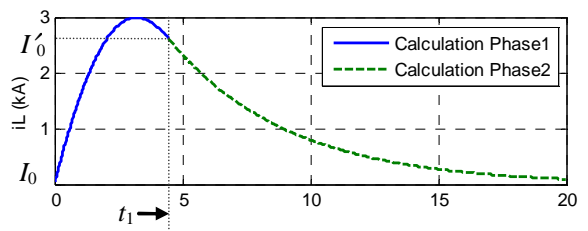

(b)

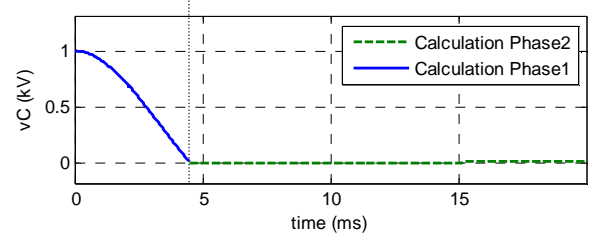

Fig. 6. Diode freewheel effect and fault time phase illustration: (a) cable inductor current $i_{L} ;$ (b) DC-link capacitor voltage $v_{C}$.

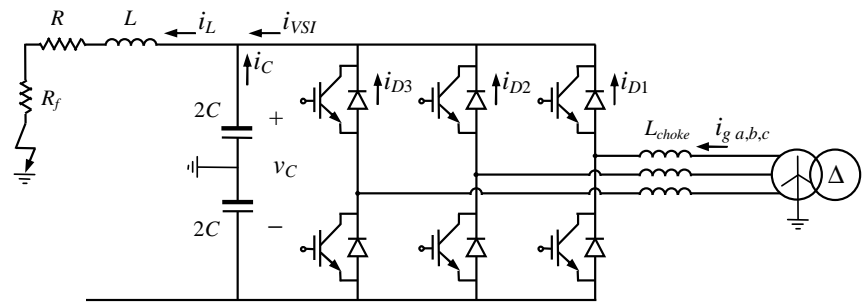

Fig. 7. VSI with positive cable ground fault condition.

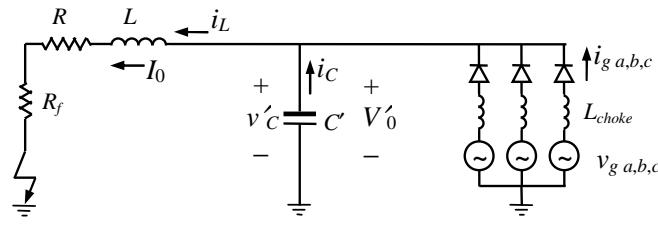

Fig. 8. Equivalent circuit for VSI with cable ground fault calculation. 
(a)

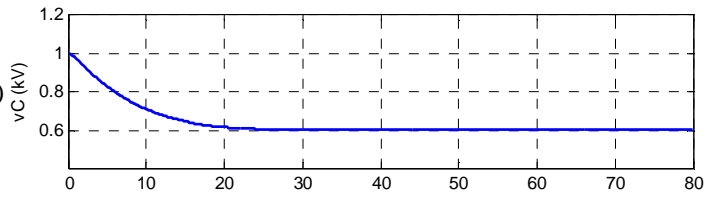

(b)

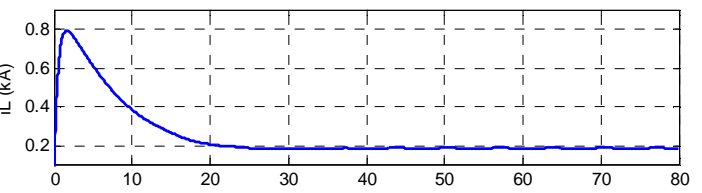

(c)

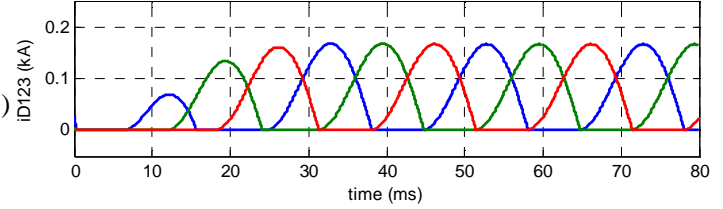

Fig. 9. Simulation results of VSI with cable ground fault: (a) DC-link capacitor voltage $v_{C}$; (b) cable inductor current $i_{L}$; (c) three-phase diode overcurrents $i_{D} 1,2,3$.

TABLE II SIMULATION PARAMETERS AND CALCULATION FOR GROUND FAULT

\begin{tabular}{c||c}
\hline Simulation system parameters & Calculation values \\
\hline$R=0.06 \Omega$ & $V_{g}=0.392 \mathrm{kV}$ \\
\hline$L=0.28 \mathrm{mH}, L_{\text {choke }}=8 \mathrm{mH}$ & $Z=2.36 \angle 88.96^{\circ}$ \\
\hline$C^{\prime}=2 C=20 \mathrm{mF}$ & $I_{g}=0.392 / 2.36=0.1661 \mathrm{kA}$ \\
\hline$R_{f}=0.5 \Omega$ & \\
\hline
\end{tabular}

TABLE III FAULT CHARACTERISTIC SUMMARY

\begin{tabular}{|c|c|c|c|c|c|}
\hline \multicolumn{2}{|c|}{ Fault type } & $\begin{array}{l}\mathrm{AC} \\
\text { faults }\end{array}$ & Short-circuit & $\begin{array}{l}\text { Ground- } \\
\text { fault }\end{array}$ & $\begin{array}{l}\text { Open- } \\
\text { circuit }\end{array}$ \\
\hline \multicolumn{2}{|c|}{$\begin{array}{l}\text { Direction of DC-link } \\
\text { voltage change }\end{array}$} & $\uparrow$ & $\downarrow$ & $\downarrow$ & $\downarrow$ \\
\hline \multirow{3}{*}{$\begin{array}{l}\mathrm{DC} \text { side } \\
\text { fault } \\
\text { current }\end{array}$} & $\begin{array}{l}\text { Initial current } \\
\text { change }\end{array}$ & - & $\begin{array}{c}\text { Up to } 73 \text { times of } \\
\text { rating }\end{array}$ & $\begin{array}{l}\text { Up to } 5 \text { times } \\
\text { of rating }\end{array}$ & - \\
\hline & $\begin{array}{c}\text { Rise-time of } \\
\text { first wave front }\end{array}$ & - & $<5 \mathrm{~ms}$ & $\begin{array}{l}>0.25\left(1 / f_{s}\right) \\
\quad=5 \mathrm{~ms}\end{array}$ & - \\
\hline & $\begin{array}{c}\text { Oscillation } \\
\text { pattern }\end{array}$ & - & $\mid \begin{array}{c}R L C \text { discharging, } \\
R L \text { diode freewheel }\end{array}$ & sinusoidal & - \\
\hline
\end{tabular}

$f_{s}$ - the synchronous time frequency.

\section{DC Cable Open-Circuit Fault}

Open-circuit faults will only influence generator side converters but not grid side converters, although this can influence the online AC grid system because of the abrupt generation loss. The disruption of energy transmission path means redundant energy generated by the turbine-generator system will cause overvoltage behind the rectifier and also generator acceleration and over-speed. This can be solved by applying dumping load at the generator AC side or a DC-chopper after the rectifier to limit the rectified DC overvoltage. Energy storage systems (ESS) could also be used at the rectifier DC-link [24].

\section{Fault Characteristic Summary}

The DC-link voltage change can be used to separate AC faults from DC faults. For AC faults, the redundant energy that can not be transferred to grid is stored in DC-link capacitor and results in the increase of DC-link voltage. But for inner DC faults, the DC-link voltage will collapse. Fault overcurrent is characterised in three aspects: initial current change, first wave rise-time, and oscillation pattern, in Table III, which could be used for fault type identification and detection.

\section{DC FAult PRoteCtion Methods}

The above DC fault analysis and detection can be applied to the design of the protection system. The main principles are the same with $\mathrm{AC}$ distribution system protection: time-response, selectivity, and reliability. There are few published works on DC system protection with DC circuit breaker and relay configuration. Most reported methods avoid using DC circuit breakers, because of the lag in development and the cost. Moreover, no relay experience can be gained from the traditional HVDC systems. In most cases, the DC faults discussed here have similar characteristics to the DC-link voltage collapse but with different amplitudes of overcurrent. Hence overcurrent protection with a directional element can realise fault location without communication between the two switchgears at the terminals of a long cable. The selectivity can be realised by using relay time delay or time coordination curves.

\section{A. DC Switchgear}

There are some options for switchgear: 1) ACCB \& DC Switch: AC side circuit breakers are used for fault current extinguishing, coordinating with DC fast switches [15]. 2) DCCB: fullyfunctioned DC circuit breaker - the optimal option. 3) Fuse: used for systems that only requires fast response for protection and no need for re-energise the system automatically. Fuses could be used at each generator's converter output side as shown in Fig. 1. Considering the strict time-response requirement, $\mathrm{AC}$ circuit breakers will not be suitable.

DC circuit breakers are required for the collection and transmission systems as they require fast response under DC fault conditions. The AC side breaker and DC switch coordination obviously cannot function fast enough; when the fault occurs, the mechanical arc-extinguishing AC side breakers operation time cannot avoid the diode freewheel effect analysed above, hence is not capable of fast fault clearance. Moreover, the allocation of DC breakers can enhance the system reliability, especially for the loop network topology, in which the AC side breakers and DC switches can only be used for a "cut-and-try" method as proposed in [15].

Detailed design of DC circuit breakers and appropriate fuse selection is required to satisfy issues such as effective arcextinguishing and fault clearance. This is a big challenge for DC circuit breaker device design.

\section{B. Measurement and Relaying Configuration}

The main protection should operate as fast as possible, with one backup protection, operating after a time delay in case the main protection malfunctions. However, the backup protection still needs to be fast enough to avoid the freewheel effect, which is less than $5 \mathrm{~ms}$ in the above example. Therefore the protection time response should be at millisecond level, depending on the protection coordination (selection) method. Distance protection is usually applied. The main principle of it is to estimate the impedance between the relay point and the fault point. If this falls into a given distance value, the relay system waits for a corresponding time delay to realise selection.

\section{1) Communication Solution:}

If each cable section is not too long, the relay detecting opposite current flow will communicate with its former relay. If their current directions are the same, then the fault has occurred outside this section. The relay will wait for a delay time. Otherwise, the fault is between the relays and this relay operates 
immediately. Because there is no further circuit breaker at the terminal of a string or star, the circuit breaker at this relay point will trip instantly. If all the relay delay time is exceeded and there is still overcurrent, the circuit breaker will trip as a backup protection.

\section{2) Distance Evaluation Solution:}

The traditional AC system distance protection uses impedance to represent the distance from fault point to the relay point. The distance judgement is made with mho characteristic or an impedance circle. But for DC systems, during fault transients, the frequency changes abruptly, so no grid fundamental frequency impedance can be defined for distance protection. In three-phase AC systems, distance protection uses symmetrical component analysis to avoid the influence of fault resistance [6]. However in DC systems these are not possible. A new distance evaluation solution is proposed.

For a fast time-response protection system, if the main protection and backup coordination are capable of securely protecting the system, at the protection stage, there is no need to use time-consuming methods to accurately locate the distance to the fault point. Rough distance evaluation is enough for a relay decision. This relies on the distance characteristics of overcurrent value and critical time for the freewheel effect. The DC-link voltage and cable inductor current variation to different fault distances are shown in Fig. 10. As distance increases the fault overcurrent reduces and the time to peak current increases.

The critical time limit is when the DC-link voltage drops to zero as in Fig. 10(a). At this time, the freewheel diodes conduct. In respect of the distance $x$, the critical time is

$$
\begin{aligned}
& \quad t_{1}-t_{0}=\left[\pi-\arctan \left(V_{0} C \omega^{\prime} /\left(V_{0} C \delta-I_{0}\right)\right)\right] / \omega^{\prime} \\
& \text { where } \omega^{\prime}=\sqrt{\omega_{0}^{2} / x-\delta^{2}} .
\end{aligned}
$$

The freewheel overcurrent is the cable inductor current at this critical time. The critical freewheel current and time with respect to distance is shown in Fig. 11. The critical time is the strict upper limit for the total switchgear operation time. The currentdistance curve in Fig. 11(a) can be used for relay configuration. Examples are shown in Fig. 12. $t(n)$ is the relay time delay curve at point $(n)$. Here the critical time is used to coordinate the delay time of the relays, shown in Fig. 12(a), which is easier to apply than Fig. 12(b) method.

For DC cables, assume per $\mathrm{km}$ resistance and inductance are $r$ and $l$ respectively. The grounding capacitor is omitted here due to the relatively low voltage level and short-length collection cable between turbines. Even for high-power case where grounding capacitors are considerable, the capacitors can be considered into each side of cable's DC-link capacitor. Suppose each section has the same length, $D$, and also ignore the possible different $r$ and $l$ values for different sections due to cable rating optimisation. (The closer the cable to collection platform, the higher the current rating of the power cable.) Even though each section may have different length, if the $r-l$ ratio is constant, this will not influence distance selection performance.

Here DC voltage dividers are used for distance measurement and representation. The fault distance is evaluated by using two voltage dividers instead of a pair of voltage and current measurements. Because in a switched-mode DC system, the DC voltages and currents are rapidly changing (with on and off periods), the division of voltage by current causes calculation problems and false decisions. Moreover, the abrupt change of current may cause measurement error, while moderate voltage changes along the cable should be easy to deal with. This discontinuous DC current feature will not influence the overcurrent detection unit; the relay only operates on overcurrent.

The measurements and distance relationship are illustrated in Fig. 13. The fault voltage at switchgear relay point $(n)$ is:

$$
v_{(n)}=v_{(f t)}+x^{*} r i_{(n)}+x^{*} l \frac{d i_{(n)}}{d t}=R_{f} i_{(f t)}+x^{*}\left(r i_{(n)}+l \frac{d i_{(n)}}{d t}\right)(13)
$$

where $x^{*}$ is the real fault distance, $R_{f}$ is the fault resistance.

(a)

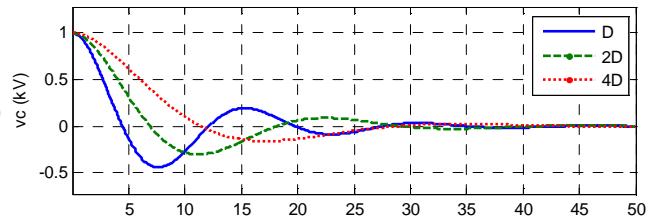

(b)

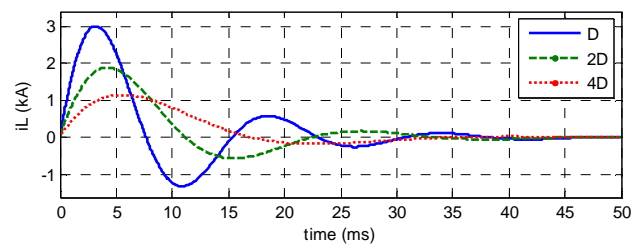

Fig. 10. Influence of fault distance on the system performance: (a) DC-link capacitor voltages of difference distances; (b) cable inductor currents of different distances.

(a)

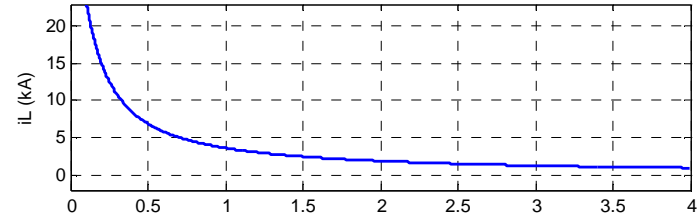

(b)

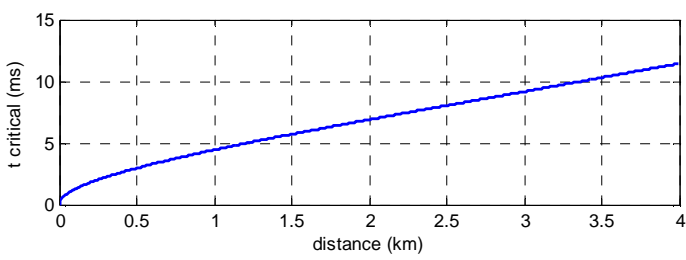

Fig. 11. Influence of fault distance on the system performance: (a) initial freewheel current according to the fault distance; (b) DC-link capacitor voltage collapse time change with distance. (Each cable section can be $1 \mathrm{~km}$ long.)

(a)

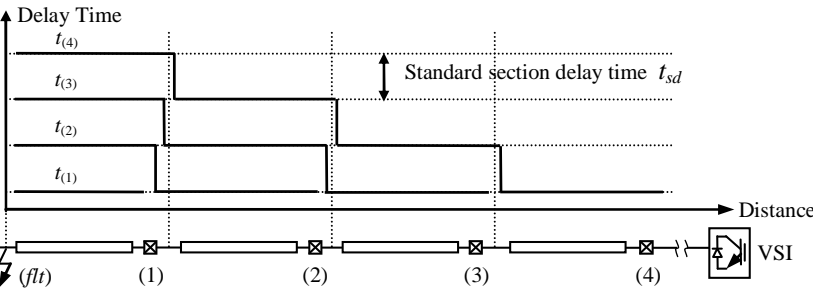

(b)

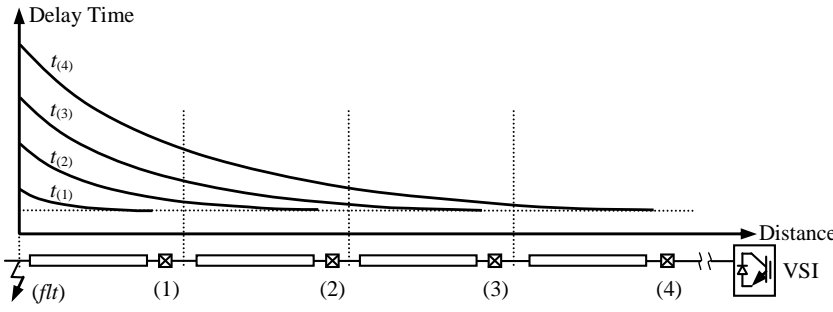

Fig. 12. Relay delay time coordination configuration: (a) with constant delay time distance relays; (b) with overcurrent-distance setting relays. 


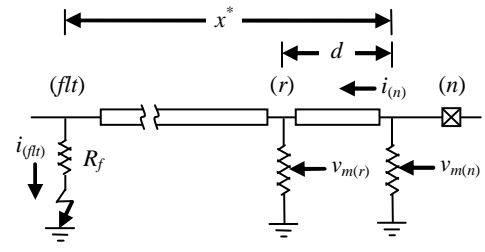

Fig. 13. Distance evaluation with two voltage divider measurements.

Another relay voltage sensor unit $(r)$ is used as reference for the relative voltage calculation; it is located near the main relay point on the same section of cable, as shown in Fig. 13, to avoid long distance communication issues. The measured value using voltage dividers are $v_{m(n)}=k_{v} v_{(n)}, v_{m(r)}=k_{v} v_{(r)}$, where $k_{v}$ is the voltage divider ratio. The distance between them is known, $d$, so the fault distance measured from this reference is

$$
x=\frac{v_{(n)}}{v_{(n)}-v_{(r)}} d=\frac{v_{m(n)}}{v_{m(n)}-v_{m(r)}} d
$$

where

$$
v_{(n)}-v_{(r)}=d\left(r i_{(n)}+l \frac{d i_{(n)}}{d t}\right) .
$$

For metallic grounding or short-circuit fault, $v_{(f f t)}=R_{f} i_{(f t t)}=0$, so the cable impedance is in proportion to distance. Measured distance $x=x^{*}$ can be used for the distance relay configuration. If the distance calculation is within a given section, the relay will operate with a corresponding time delay to realise selection as shown in Fig. 12(a). The delay time of all the sections should be less than the critical time to avoid freewheel diode overcurrent.

For high resistance faults, which are more common in ground faults, the existence of $R_{f}$ and difference between $i_{(f f t)}$ and $i_{(n)}$ make the evaluation of $x^{*}$ difficult. Usually, this kind of fault are not as serious as the metallic grounding or short-circuit, so may not require fast time-response protection hence can be fulfilled by overcurrent setting. Considering the backup configuration and the critical time limit shown in Fig. 11(b), a method to estimate the fault distance is proposed by estimating both the cable distance and equivalent fault resistance.

The distance measured in (14) in this case is not accurate because the influence of fault resistance, but this is the only information that can be used for time delay decision. (15) presents the real voltage drop between the two relay points, which reflects the real voltage drop excluding the influence of $R_{f}$ $i_{(f t t)}$. But $R_{f}$ still can not be exactly obtained even with the source side tripped, i.e. $i_{(f f t)}=i_{(n)}$. One solution is to measure the reactance to exclude the resistance influence, but this is hard to achieve. Under the assumption that the DC power source side is immediately tripped, the voltage measurement is

$$
v_{(n)}=R_{f} i_{(n)}+x^{*}\left(r i_{(n)}+l \frac{d i_{(n)}}{d t}\right)=R_{f} i_{(n)}+x^{*} r i_{(n)}(1+K)
$$

where

$$
K=\left(l \frac{d i_{(n)}}{d t}\right) /\left(r i_{(n)}\right)
$$

is the equivalent ratio of reactance to resistance voltage drops.

Then defining $R_{D}=D\left(r i_{(n)}+l \frac{d i_{(n)}}{d t}\right) / i_{(n)}=\operatorname{Dr}(1+K)$

as equivalent resistance per section. Hence the measured distance

$$
x=\frac{v_{(n)}}{v_{(n)}-v_{(r)}} d=\frac{R_{f} i_{(n)}+x^{*} r i_{(n)}(1+K)}{\left(r i_{(n)}+l \frac{d i_{(n)}}{d t}\right)}=\frac{R_{f}}{R_{D}} D+x^{*}
$$

In practical applications, it is not economical to allocate circuit breakers at each collection unit end in a collection string. For a string with 10 turbines, the total number of circuit breakers can be 3 or 4 , so the delay time will be about $4.44 / 4 \mathrm{~ms}$ in the above case. This requires the DC circuit breakers to operate at $1 \mathrm{~ms}$ level, which is achievable. The evaluation decision procedure is shown in the distance estimation table (Table IV), used for coordination, to

\begin{tabular}{|c|c|c|c|c|c|}
\hline Relay & $\begin{array}{c}\text { Fault } \\
\text { distance }\end{array}$ & $\begin{array}{c}\text { Fault } \\
\text { region }\end{array}$ & $\begin{array}{c}\text { Fault } \\
\text { resistance }\end{array}$ & $\begin{array}{c}\text { Confidence in } \\
\text { Discrimination }\end{array}$ & $\begin{array}{l}\text { Switch } \\
\text { Delay }\end{array}$ \\
\hline \multirow{2}{*}{ (1) } & $x \leq D$ & (1)-(0) & -- & Yes & 0 \\
\hline & $x>D$ & $(1)-(0)$ & $R_{f}>0$ & Yes & 0 \\
\hline \multirow{5}{*}{ (2) } & $x \leq D$ & (2)-(1) & -- & Yes & 0 \\
\hline & \multirow{2}{*}{$D<x \leq 2 D$} & (2)-(1) & $R_{f} \geq R_{D}$ & \multirow{2}{*}{ No } & \multirow{2}{*}{$t_{s d}$} \\
\hline & & $(1)-(0)$ & $0 \leq R_{f}<R_{D}$ & & \\
\hline & \multirow{2}{*}{$x>2 D$} & $(2)-(1)$ & $R_{f} \geq 2 R_{D}$ & \multirow{2}{*}{ No } & \multirow{2}{*}{$2 t_{s d}$} \\
\hline & & (1)-(0) & $0 \leq R_{f}<R_{D}$ & & \\
\hline \multirow{9}{*}{ (3) } & $x<D$ & (3)-(2) & -- & Yes & 0 \\
\hline & \multirow{2}{*}{$D<x \leq 2 D$} & (3)-(2) & $R_{f} \geq R_{D}$ & \multirow{2}{*}{ No } & \multirow{2}{*}{$t_{s d}$} \\
\hline & & (2)-(1) & $0 \leq R_{f}<R_{D}$ & & \\
\hline & \multirow{3}{*}{$2 D<x \leq 3 D$} & (3)-(2) & $R_{f} \geq 3 R_{D}$ & \multirow{3}{*}{ No } & \multirow{3}{*}{$2 t_{s d}$} \\
\hline & & (2)-(1) & $R_{D} \leq R_{f}<2 R_{D}$ & & \\
\hline & & $(1)-(0)$ & $0 \leq R_{f}<R_{D}$ & & \\
\hline & \multirow{3}{*}{$x>3 D$} & (3)-(2) & $R_{f} \geq 3 R_{D}$ & \multirow{3}{*}{ No } & \multirow{3}{*}{$3 t_{s d}$} \\
\hline & & (2)-(1) & $R_{D} \leq R_{f}<2 R_{D}$ & & \\
\hline & & $(1)-(0)$ & $0 \leq R_{f}<R_{D}$ & & \\
\hline
\end{tabular}
allocate both main protection and backup protection. The standard section delay time $t_{s d}$ for coordination is calculated according to the critical time divided by the corresponding section number.

TABLE IV DistANCE PROTECTION RELAY TIME COORDINATION

A three-section example is shown in Table IV. For the relay (1) at the far end of a string cable, the measured distance only falls into 2 conditions. No matter what is the measured $x$ value, the circuit breaker will immediately operate when overcurrent detected. For relay (2), if $x \leq D$, it is certain that the fault is happened inside cable between (2) and (1), so delay time is also 0 . But if $x>D$, whether it is smaller than $2 D$ or not, it is hard to decide whether cable (2)-(1) or (1)-(0) is faulted. But the bigger the evaluated distance $x$, the less serious is the fault, so the time delay is set as backup standard, with one $t_{s d}$ delay or $2 t_{s d}$ delay when $x>2 D$. The closer the relay is to the inverter, the more possibilities there are to assess, and the longer the time available for distance measurement. The evaluation procedure using different distance calculation values to set relay delay times, to distinguish the main and backup protections. This ensures that the fault is cleared by at least the backup protection.

\section{Small-scale System Protection Option}

A simple method is proposed for small-scale, low-power scenarios. Reverse diodes can be used to restrain the fault current from flowing into DC cable system. The VSI diodes clamp the voltage after the DC-link capacitor, another pair of diodes can be used before the DC-link to block the fault current flowing in the other direction. In this way, the DC-link voltage will not change abruptly. DC-chopper circuit is used in case of DC-link overvoltage. The reverse diode positions and current flows are shown in Fig. 14.

PSCAD/EMTDC simulations are carried out. The simulated system topology is a DC wind farm collection grid with dioderectifier and DC/DC boost conversion in parallel with the grid side inverter. This is economical and practical for small-scale systems. 
The simulated DC wind farm system includes two equivalent parallel connected wind turbine generation systems. The faults simulated are: 1) a short-circuit fault for $1.0 \mathrm{~s} ; 2$ ) a cable ground fault for 1.0s. Both happen on the cable of one generation system. Zero fault resistance is considered to give the most serious condition.

The DC-link capacitor voltage and inverter side reverse currents are shown in Fig. 15. For a short-circuit fault, the DC-link voltage is clamped to be around pre-fault value and no current flows through the diodes to charge the capacitor, i.e. the inverter current is almost zero in Fig. 15(b), compared with that of up to $2.50 \mathrm{kA}$ in Fig. 15(a). The overvoltage after the recovery of fault will be reduced by the DC-chopper. For a ground-fault condition, no DCchopper is needed. There is an inverter overcurrent, but this is limited to 2 times of the normal value, which is tolerable for devices.

\section{DC Wind FARM PROTECTION SIMULATION RESULTS}

The proposed protection method is applied to specific DC wind farm systems and verified by PSCAD/EMTDC simulations. The topologies investigated are small-scale DC wind farm collection grids with star and string connections respectively. The generators are permanent magnet synchronous generators (PMSGs). The generator side AC/DC converters are three-phase diode-rectifiers connected to boost DC/DC converters for energy conversion and maximum power point tracking. The simulated DC wind farm system includes two equivalent wind turbine generation systems, parallel connected, to the DC-link and grid side inverter. The faults simulated are: 1) for star connection, a short-circuit fault on the cable of one collection unit; 2) for string connection, a grounding fault on the collection cable of one unit near the inverter side. The generator and DC cable parameters are provided in the Appendix.

\section{A. Short-Circuit Fault Condition}

Fig. 16 shows the system performance under a short-circuit fault at $t=3.0 \mathrm{~s}$ at the mid-point of one collection cable of a generation system. To show the selection validity, this fault is applied to star connection and the fault point is on one collection unit cable. The selectivity should make sure this fault will not influence the power transferred to the inverter from the other turbine system. The protection opens the faulted side circuit breaker immediately. The total power transmitted to the onshore grid drops to 0.5p.u.. The VSI control maintains the DC-link voltage constant with a slight transient, Fig. 16(a). In Fig. 17, the currents at the two relay points show that, under voltage control, the current at the grid switchgear relay point (3) $i_{(3)}$ drops to a half due to the trip of circuit breaker $(1)\left(i_{(1)}=0\right)$, hence the total power decreases by a half.

In Fig. 18 currents and voltages are scaled to show the time response of protection system. The overcurrent relay threshold is set to be $1.5 p$.u. (60A). It takes about $70 \mu$ s to reach that value and then immediate switching is carried out. The DC circuit breaker simulated is a self-defined PSCAD model of bidirectional IGBT/diode switch, with gate control from the relay system. The actual minimum extinction time for the IGBT is set as $10 \mu \mathrm{s}$ in this case, which is adequate for IGBTs (commonly several $\mu \mathrm{s}$ [25]). Hence in total it takes $80 \mu$ s to actually

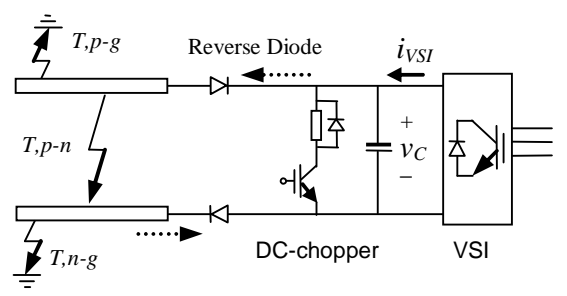

Fig. 14. The reverse diode protection method and current flow directions.
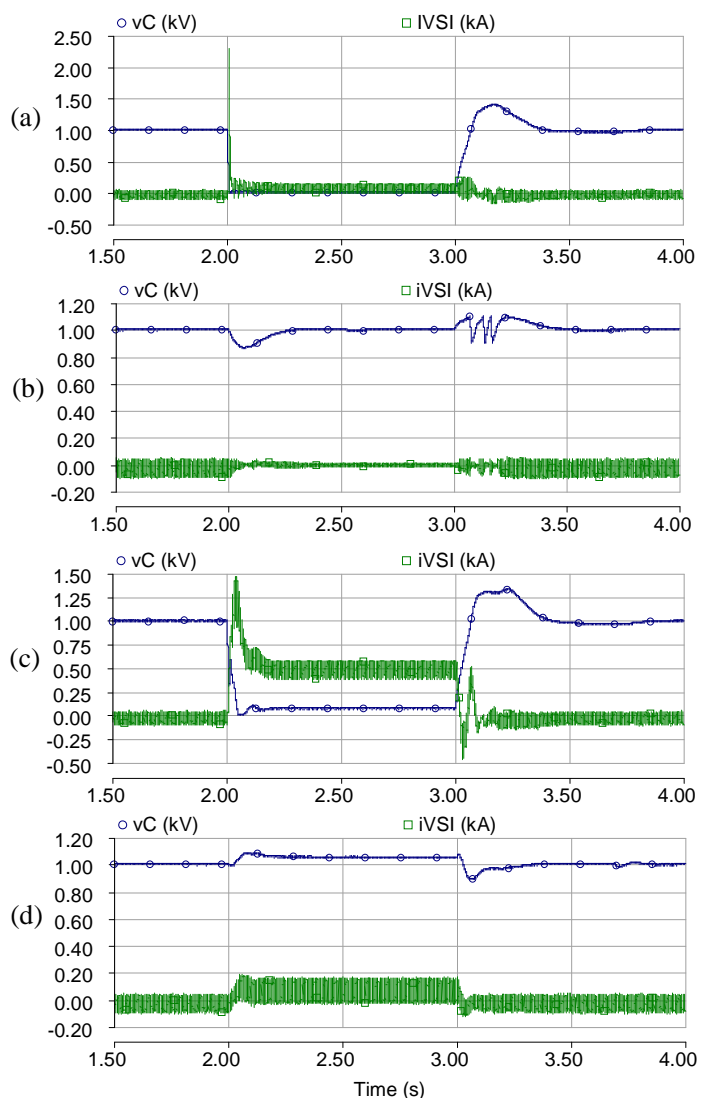

Fig. 15. The reverse diode and DC-chopper protection method performance (DClink capacitor voltage $v_{C}$ and VSI current $i_{V S I}$ ) simulation: (a) short-circuit fault without protection; (b) short-circuit fault with protection; (c) cable ground fault without protection; (d) cable ground fault with protection.

extinguish the fault current, much less than the freewheel effect time, $5.1 \mathrm{~ms}$ for the fault distance of $1.25 \mathrm{~km}$ (calculated from (11) and shown in Fig. 11(b)).

The voltage measurements used for distance evaluation are shown in Fig. 18(b). After the fault occurs, the relay point (1) voltage $v_{(1)}$ drops to about $0.1 \mathrm{kV}$, with a reference measurement $(1 r)$ voltage $v_{(1 r)}$ at about $0.05 \mathrm{kV}$. According to distance evaluation equation (16), $x=0.1 d /(0.1-0.05)=0.25 \mathrm{~km}$, where $d$ is known as $0.125 \mathrm{~km}$. This is less than the cable length of $0.5 \mathrm{~km}$, which means the overcurrent relay should operate without time delay as long as it detects reverse overcurrent exceeding the 1.5p.u. threshold value. Moreover, the evaluated distance is accurate (at the mid-point of the $0.5 \mathrm{~km}$ collection cable), because the short-circuit resistance is zero in this case. Here it is assumed that the measurements and calculation can be completed within the time in which the overcurrent is reached - about 60 $\mu$ s in Fig. 18(b).

\section{B. Cable Ground Fault Condition}

The cable ground fault protection performance is shown in Fig. 19. The ground fault with resistance of $5 \Omega$ occurs on the second 
collection cable in a collection string (also the mid-point), so the switchgear trip means there will be no power flow to the grid, as shown in Fig. 19(b). Fig. 20 shows the collection cable (2)-(1) DC circuit breaker relay (2) current and voltage measurements. At the instant of the fault, $t=3.0 \mathrm{~s}$, the current direction is opposite; it feeds current into the fault. Although the direction element can detect the fault current direction change, the overcurrent threshold 1.5p.u. is not reached, so no trip occurs until the delay time has passed. The evaluated fault distance includes the influence of fault resistance, hence it is possible to misjudge the fault location. The fault resistance can restrict the overcurrent so it is not as severe as metallic fault conditions. The time delay is set as calculated from the fault distance and delay time concept. Evaluated distance value of relay (2) $x$ is intolerable now (an unreasonably large value, much larger than the total collection length $-1 \mathrm{~km}$ ) because of the high fault resistance. So the time delay of (2) is set to be that for $1 \mathrm{~km}-4.44 \mathrm{~ms}$ in Fig. 20, for (3) is the total value of critical time for the total $2 \mathrm{~km}$ cable $-6.89 \mathrm{~ms}$. Fig. 21 shows the circuit breaker switch timing at relay point (2).

\section{CONCLUSION}

DC system protection for wind farms is a new area primed by the potential development of multi-terminal DC wind farms. In this paper, internal DC faults are listed and analysed in detail, including the most critical short-circuit fault and cable ground faults. The ov-

(a)

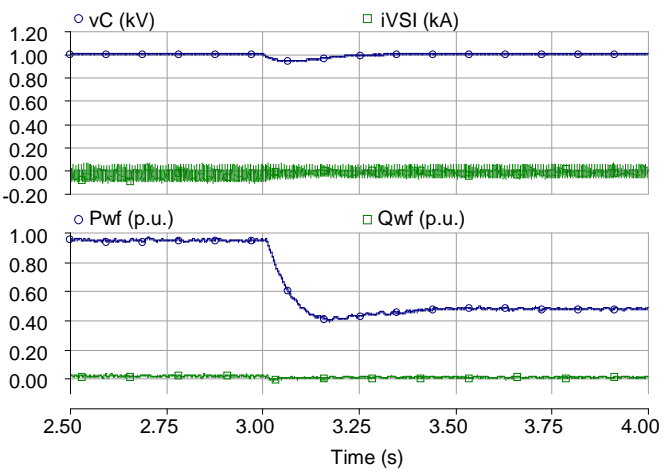

Fig. 16. The wind farm performance under short-circuit fault at one turbinegenerator collection unit cable in star connection: (a) DC-link capacitor voltage $v_{C}$ $(\mathrm{kV})$ and VSI current $i_{V S I}(\mathrm{kA})$; (b) wind farm total active and reactive power $P_{w f}$ (p.u.), $Q_{w f}$ (p.u.).

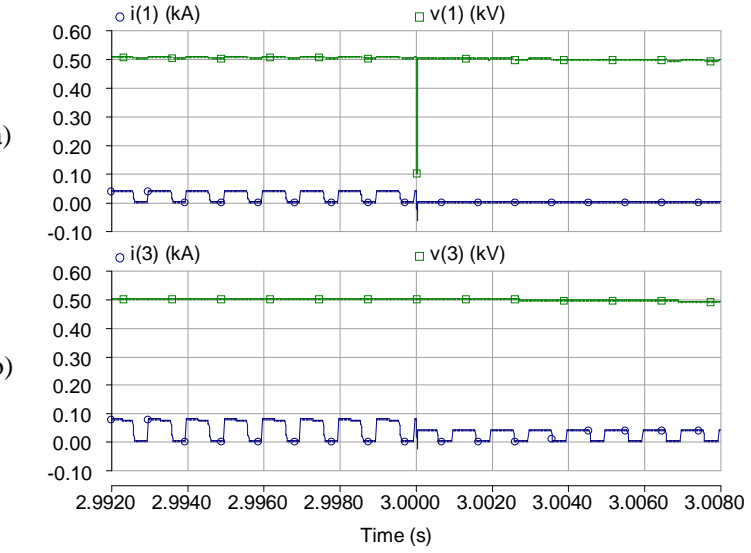

Fig. 17. The relay measurements under short-circuit fault at the first wind turbine collection unit, star connection: (a) current and voltage measurements at relay point (1) of the faulted cable, $i_{(1)}(\mathrm{kA})$ and $v_{(1)}(\mathrm{kV})$; (b) current and voltage measurements at relay point (3) of the transmission cable, $i_{(3)}(\mathrm{kA})$ and $v_{(3)}(\mathrm{kV})$. -ercurrent and DC voltage drop characteristics can instruct DC switchgear relay design and selection. The study of common VSC and cable circuit fault can be used for most VSC-based DC topologies. A detailed protection design and relay coordination method is proposed, with a diode clamping method for small-scale systems in which DC circuit breakers are not economically feasible. Simulation results show that the proposed methods are effective for system protection.

The transmission system can be meshed to enhance the reliability but this is a big challenge for DC protection and relay design. Although expensive, it is still necessary to have DC circuit breakers for a power transmission system. There has been much research about the design of fully-functioned economical DC circuit breakers. In the future, this would not be a limitation on DC power system development. The challenge of protecting meshed DC wind farm networks is currently under study and will be reported in future papers. The focus of this study has been a smallscale DC wind farm. While the conclusions may extend, suitably modified, to large-scale DC wind farms, this remains an area for further investigation.

(a)

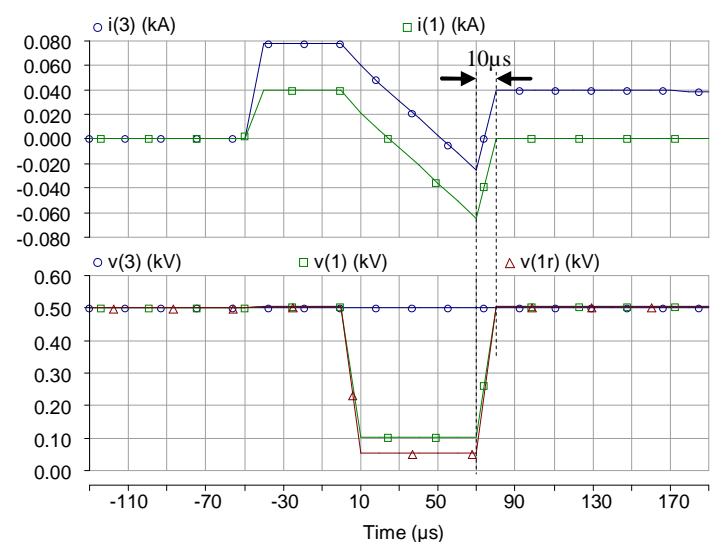

Fig. 18. The zoomed relay measurements under short-circuit fault condition: (a) current measurements; (b) voltage measurements including relay (1) reference voltage $v_{(1 r)}(\mathrm{kV})$.

(a)

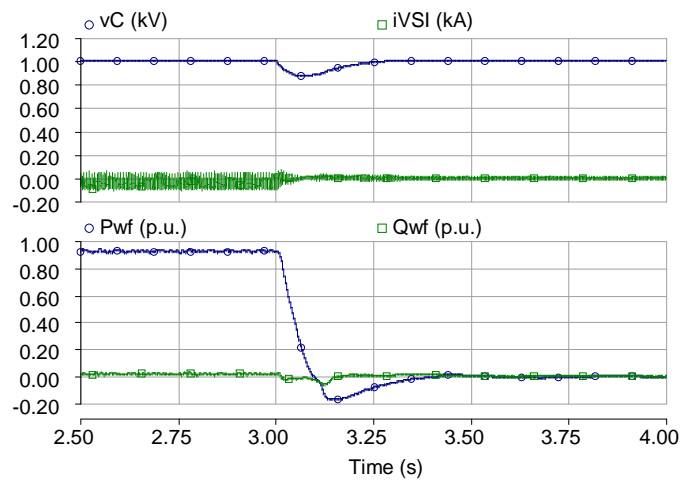

Fig. 19. The wind farm performance under cable ground fault at the second turbinegenerator collection unit cable in string connection: (a) DC-link capacitor voltage $v_{C}(\mathrm{kV})$ and VSI current $i_{V S I}(\mathrm{kA})$; (b) wind farm total active and reactive power $P_{w f}$ (p.u.), $Q_{w f}$ (p.u.)

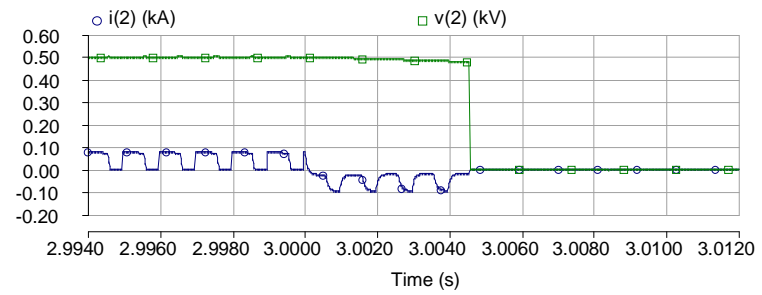

Fig. 20. The relay measurements under cable ground fault condition, at the relay point (2), current $i_{(2)}(\mathrm{kA})$ and voltage $v_{(2)}(\mathrm{kV})$. 
(a)

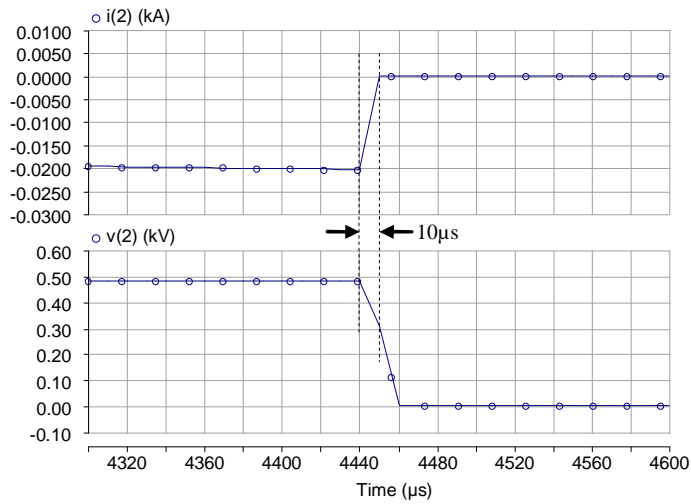

Fig. 21. The zoomed relay measurements under ground fault condition: (a) relay current measurement; (b) relay voltage measurement.

\section{APPENDIX}

TABLE V PMSG PARAMETERS

\begin{tabular}{l|l||l|l}
\hline Parameter & Value & Parameter & Value \\
\hline Rated power $P_{n}$ & $25 \mathrm{~kW}$ & Pole pair no. $P_{p}$ & 12 \\
\hline Rated stator voltage $V_{s n}$ & $450 \mathrm{~V}$ & Phase resistance & 0.068 p.u. \\
\hline Rated frequency $f_{g}$ & $30 \mathrm{~Hz}$ & Phase inductance & 0.427 p.u. \\
\hline
\end{tabular}

TABLE VI DC CABLE PARAMETERS

\begin{tabular}{l|l||l|l}
\hline Parameter & Value & Parameter & Value \\
\hline Resistance $r$ & $0.06 \Omega / \mathrm{km}$ & Collection cable (1)-(0) & $0.5 \mathrm{~km}$ \\
\hline Inductance $l$ & $0.28 \mathrm{mH} / \mathrm{km}$ & $\begin{array}{l}\text { Collection cable } \\
(2)-(0) \text { for star / (2)-(1) for string }\end{array}$ & $0.5 \mathrm{~km}$ \\
\hline Rating voltage & $1 \mathrm{kV}$ & Transmission cable (3)-(2) & $1.0 \mathrm{~km}$ \\
\hline
\end{tabular}

\section{REFERENCES}

[1] P. Bresesti, W. L. Kling, R. L. Hendriks, and R. Vailati, "HVDC connection of offshore wind farms to the transmission system," IEEE Trans. Energy Convers., vol. 22, no. 1, pp. 37-43, Mar. 2007.

[2] C. Meyer, M. Hoing, A. Peterson, and R.W. De Doncker, "Control and design of DC grids for offshore wind farms," IEEE Trans. Ind. Appl., vol. 43, no. 6, pp. 1475-1482, Nov./Dec. 2007

[3] A. Prasai, J. S. Yim, D. Divan, A. Bendre, and S. K. Sul, "A new architecture for offshore wind farms," IEEE Trans. Power Electron., vol. 23 , no. 3, pp. 1198-1204, May 2008.

[4] D. Jovcic and N. Strachan, "Offshore wind farm with centralised power conversion and DC interconnection," IET Gener. Transm. \& Distrib., vol. 3 , no. 6, pp. 586-595, Jun. 2009

[5] P. M. Anderson, Power system protection. New York: IEEE Press, 1999

[6] X. Yang, M.-S. Choi, S.-J. Lee, C.-W. Ten, and S.-I. Lim, "Fault location for underground power cable using distributed parameter approach," IEEE Trans Power Sys., vol. 23, no. 4, pp. 1809-1816, Nov. 2008.

[7] M.-S. Choi, S.-J. Lee, D.-S. Lee, and B.-G Jin, "A new fault location algorithm using direct circuit analysis for distribution systems," IEEE Trans. Power Del., vol. 19, no. 1, pp. 35-41, Jan. 2004.

[8] X. Liu, A. H. Osman, and O. P. Malik, "Hybrid travelling wave/boundary protection for monopolar HVDC line," IEEE Trans. Power Del., vol. 24, no. 2, pp. 569-578, Apr. 2009

[9] L. Xu, B. R. Andersen, and P. Cartwright, "VSC Transmission System Operating under Unbalanced Network Conditions - Analysis and Control Design”, IEEE Trans. Power Del, vol. 20, no. 1, pp. 427-434, Jan.2005.

[10] L. Xu, L. Yao, M. Bazargan, and A. Yan, "Fault ride through of large offshore wind farms using HVDC transmission," in Proc. 2009 IEEE Power Tech Conf., Bucharest, Romania, 28 Jun. - 2 Jul., 2009.

[11] M. E. Baran and N. R. Mahajan, "DC distribution for industrial systems: opportunities and challenges," IEEE Trans. Ind. Appl., vol. 39, no. 6, pp. 1596-1601, Nov./Dec. 2003.

[12] M. E. Baran and N. R. Mahajan, "Overcurrent protection on voltage-sourceconverter-based multiterminal DC distribution systems," IEEE Trans. Power Del., vol. 22, no. 1, pp. 406-412, Jan. 2007.

[13] F. Blaabjerg and J. K. Pederson, "A new low-cost, fully fault-protected PWM-VSI inverter with true phase-current information," IEEE Trans. Power Electron., vol. 12, no. 1, pp. 187-197, Jan. 1997.
[14] L. Tang and B. T. Ooi, "Protection of VSC-multi-terminal HVDC against DC faults," in Proc. IEEE 33rd Annual Power Electronics Specialists Conf., vol. 2, pp. 719-724, Cairns, Queensland, Australia, 23-27 Jun. 2002.

[15] L. Tang and B. T. Ooi, "Locating and isolating DC faults in multi-terminal DC systems," IEEE Trans. Power Del., vol. 22, no. 3, pp. 1877-1884, Jul. 2007.

[16] D. Xiang, R. Li, P. J. Tavner, and S. Yang, "Control of a doubly fed induction generator in a wind turbine during grid fault ride-through," IEEE Trans. Energy Convers., vol. 21, no. 3, pp. 652-662, Sep. 2006.

[17] I. Erlich, J. Kretschmann, J. Fortmann, S. Mueller-Engelhardt, and H. Wrede, "Modeling of wind turbines based on doubly-fed induction generators for power system stability studies," IEEE Trans. Power Syst., vol. 22, no. 3, pp. 909-919, Aug. 2007.

[18] M. E. Haque, M. Negnevitsky, and K. M. Muttaqi, "A novel control strategy for a variable speed wind turbine with a permanent magnet synchronous generator," in Proc. Ind. Appl. Society Annual Meeting, Hobart, Australia, 5-9 Oct. 2008.

[19] A. D. Hansen and G. Michalke, "Multi-pole permanent magnet synchronous generator wind turbines' grid support capability in uninterrupted operation during grid faults," IET Renewable Power Gener., vol. 3, no. 3, pp. 333-348, Sep. 2009

[20] H. A. Darwish, A.-M. I. Taalab, and M.A. Rahman, "Performance of HVDC converter protection during internal faults," in Proc. IEEE Power Eng. Society General Meeting, pp. 57-59, Montreal, Quebec, Canada, 18-22 Jun. 2006.

[21] M. J. Mousavi and K. L. Butler-Purry, "A novel condition assessment system for underground distribution applications," IEEE Trans. Power Sys., vol. 24, no. 3, pp. 115-1125, Aug. 2009.

[22] S. R. Mendis, M. T. Bishop, J. C. McCall, and W. M. Hurst, "Overcurrent protection of capacitors applied on industrial distribution systems," IEEE Trans Ind. Appl., vol. 29, no. 3, pp. 541-547, May/Jun. 1993.

[23] K. Xing, F. C. Lee, J. S. Lai, T. Gurjit, and D. Borojevic, "Adjustable speed drive neutral voltage shift and grounding issues in a DC distribution system," in Proc. IEEE Ind. Appl. Society Annual Meeting, New Orleans, Louisiana, 5-9 Oct. 1997.

[24] C. Abbey, W. Li, L. Owatta, and G. Joós, "Power electronic converter control techniques for improved low voltage ride through performance in WTGs," in Proc. $37^{\text {th }}$ IEEE Power Electronics Specialists Conference, vol. 1, pp. 422-427, Jeju, Korea, 18-22 Jun. 2006.

[25] S. Castagno, R. D. Curry, and E. Loree, "Analysis and comparison of a fast turn-on series IGBT stack and high-voltage-rated commercial IGBTs," IEEE Trans. Plasma Science, vol. 34, no. 5, pp 1692-1696, Oct. 2006

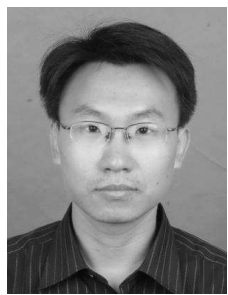

Jin Yang (S'08) was born in Liaoning, China, in 1980. $\mathrm{He}$ received the B.Eng. and M.Sc. degrees from North China Electric Power University, Baoding, China, in 2003 and 2006, respectively.

$\mathrm{He}$ is now pursuing the Ph.D. degree in the Department of Electronics and Electrical Engineering, University of Glasgow, Glasgow, U.K. His research interests include wind power generation system protection and wind power economics.

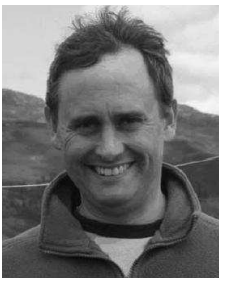

John E. Fletcher received the B.Eng. (first class honours) and Ph.D. degrees from Heriot-Watt University, Edinburgh, U.K. in 1991 and 1995, respectively, both in Electrical and Electronic Engineering.

Until 2007, he was with Heriot-Watt University and is currently Senior Lecturer at the University of Strathclyde, Glasgow, UK. His research interests include power electronics, drives and energy conversion, and manages research projects including distributed and renewable integration, silicon-carbide electronics, pulsed-power applications of power electronics and the design and control of electrical machines. Dr. Fletcher is a Chartered Engineer in the U.K. and a Fellow of the Institution of Engineering and Technology.

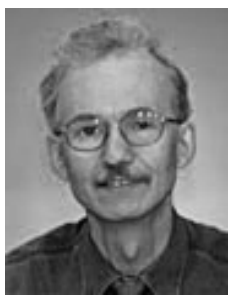

John O'Reilly (M'81-SM'00) received the B.Sc., Ph.D., and D.Sc. degrees in engineering from Queens University, Belfast, U.K., in 1972, 1976, and 1985, respectively.

Currently, he is a Professor of Control engineering in the Department of Electronics and Electrical Engineering, University of Glasgow, Glasgow, U.K. His interests include power system dynamics and control with renewable energy. 